\title{
Afatinib reverses ceritinib resistance (CR) in ALK/ROSI-positive non-small-cell lung cancer cell (NSCLC) via suppression of NRGI pathway
}

This article was published in the following Dove Press journal: OncoTargets and Therapy

\author{
Hui Chen ${ }^{1-4}$ \\ Qiang Zhang ${ }^{1-4}$ \\ Yu Zhang ${ }^{1-4}$ \\ Bin Jia ${ }^{1-4}$ \\ Bin Zhangl-4 \\ Changli Wang ${ }^{1-4}$ \\ 'Department of Lung Cancer,Tianjin \\ Medical University Cancer Institute \\ and Hospital, National Clinical \\ Research Center for Cancer, Tianjin, \\ People's Republic of China; ${ }^{2}$ Key \\ Laboratory of Cancer Prevention and \\ Therapy, Tianjin, People's Republic \\ of China; ${ }^{3}$ Tianjin's Clinical Research \\ Center for Cancer, Tianjin, People's \\ Republic of China; ${ }^{4}$ Tianjin Lung \\ Cancer Center, Tianjin, People's \\ Republic of China
}

Background: Lung cancer (LC) is the most prevalent malignancy worldwide, and non-small-cell LC (NSCLC) cell is associated with high mortality. As a member of the second generation of anaplastic lymphoma kinase (ALK) suppressors, ceritinib has considerable therapeutic effects for ALK and c-ros oncogene 1 (ROS1)-positive NSCLC cell. Nevertheless, patients inevitably develop resistance to the drug. Our research focused on the exploration of whether afatinib was able to counteract ceritinib resistance (CR) in NSCLC cells with positive ALK or ROS1.

Materials and methods: Acquired CR cell sublines (HCC78R and H1299R) were induced by stepwise escalation of ceritinib exposure. MTT assay was used to validate cell proliferation. Fluorescence assay was performed for apoptosis analysis. Quantitative real-time PCR and Western blot assays were used to assess the alterations of signaling pathway-related mRNA and proteins, respectively.

Results: We found that prolonged treatment of HCC78 and $\mathrm{H} 1299$ with ceritinib brought about 10 times weaker ceritinib sensitivity (CS) in comparison with parent cells. Additionally, the results showed that afatinib efficiently promoted CS, which was evidenced as reduced proliferation and cell death promotion, in NSCLC cells, irrespective of their previous sensitivity or resistance to ceritinib. Moreover, afatinib decreased neuregulin-1 (NRG1) signaling stimulation in CR as well as CS cells. Furthermore, supplementing NRG1 in H1299 and HCC78 cells triggered CR, which was attenuated by afatinib.

Conclusion: These results demonstrated that afatinib overcame CR in NSCLC cells with positive ALK or ROS1 by inhibiting the NRG1 signaling pathway, which might be a promising therapeutic approach.

Keywords: afatinib, ceritinib, NRG1, lung cancer, ALK/ROS1

\section{Introduction}

Lung cancer (LC) is the most prevalent malignancy worldwide; $80 \%$ of the associated mortality is attributable to non-small-cell LC (NSCLC) cell. ${ }^{1}$ Chromosomal changes or somatic mutations leading to the stimulation of protein kinase are responsible for cancer generation. Anaplastic lymphoma kinase (ALK) was the first identified fusion oncokinase, held accountable for $4 \%-6 \%$ of pulmonary adenocarcinomas. ${ }^{2}$ ALK rearrangements have been reported in various cancers such as NSCLC, providing a novel target for treating a proportion of NSCLCs. ${ }^{3}$ c-ros oncogene 1 (ROS1) is a member of the receptor tyrosine kinase family, which generates fusions and defines additional active oncogenic driver mutations with regard to NSCLC. ${ }^{4,5}$ Recent studies have proved that almost $1.4 \%$ of NSCLCs display rearrangements in ROS1. The discovery of selective and promising suppressors of ALK as well as ROS1 kinase has promoted
Correspondence: Changli Wang Department of Lung Cancer, Tianjin Medical University Cancer Institute and Hospital, National Clinical Research Center for Cancer Tianjin, Huan-Hu-Xi Road, Ti-Yuan-Bei, He Xi District, Tianjin 300060, People's Republic of China Tel +86 I35 I2004380 Email wangchanglii@I63.com $\mathrm{BY}$
hC hereby accept the Terms. Non-commercial uses of the work are permitted without any further permission from Dove Mediect
for commercial use of this work, please see paragraphs 4.2 and 5 of our Terms (https://www.dovepress.com/terms.php). 
research utilizing these agents as an innovative therapeutic approach to treat LC with positive ROS1 and ALK.

As the earliest second-generation ALK/ROS1 suppressor, ceritinib (LDK378) received US Food and Drug Administration approval in 2014 and is currently used in NSCLC therapy for patients resistant to crizotinib. ${ }^{6-8}$ Although ceritinib is a remarkable drug, ceritinib resistance (CR) can develop. Recent research on ceritinib has reported that $60 \%$ of patients developed CR, while their cancers displayed no obvious mutations resistant to ALK. ${ }^{9,10}$ These findings indicate the possible existence of pathways besides those targeted by second-generation ALK suppressors.

Previous studies have demonstrated the existence of an autocrine loop between HER3 and its ligand NRG3 in prostate cancer, ovarian tumor, and melanoma. ${ }^{11,12}$ Research has suggested that NRG1-EGFR axis participates in the regulation of resistance to second-generation ALK suppressors such as ceritinib. ${ }^{1}$ Consequently, the neuregulin-1 (NRG1) pathway serves as a promising target to treat NSCLC with positive ALK.

Meanwhile, afatinib, also called BIBW2992, suppresses HER2 as well as EGFR irreversibly and has been approved for the treatment of NSCLC with mutated EGFR in several countries. In two randomized Phase III trials, afatinib displayed a remarkable promotion of survival without progression in comparison to standardized doublet chemotherapy for NSCLC with mutated EGFR. ${ }^{13,14}$

Therefore, we aimed to explore whether afatinib was able to recover CS in CR cells via suppression of the NRG1 axis.

\section{Materials and methods Cell culture and reagents}

NSCLC cells H1299 and HCC78 with positive ALK or ROS1 were bought from the American Type Culture Collection (ATCC) (Manassas, VA, USA). DMEM supplemented with 10\% FBS (Thermo Fisher Scientific, Waltham, MA, USA), $100 \mu \mathrm{g} / \mathrm{mL}$ streptomycin, and $100 \mathrm{U} / \mathrm{mL}$ penicillin was used for culturing under $5 \% \mathrm{CO}_{2}$ at $37^{\circ} \mathrm{C}$. Afatinib and ceritinib were bought from Selleckchem (Houston, TX, USA). NRG1 was bought from R\&D Systems, Inc. (Minneapolis, MN, USA). Cells were preserved at $-20^{\circ} \mathrm{C}$.

\section{Preparation of CR cells}

CR cells (HCC78R and H1299R) were cultivated by increasing supplementation of the agents $(1 \mu \mathrm{M})$ for 3 days. Cells resistant to agents underwent expansion and recovered growth rates similar to those of parent cells. Subsequently, cells that survived received supplement of agents for 3 additional days.
This procedure was repeated until growth rates with $1 \mu \mathrm{M}$ ceritinib were similar to those without ceritinib.

\section{Quantitative real-time PCR (qRT-PCR)}

Separation of total RNA was carried out using the Mini RNA Isolation II Kit (Zymo Research, Orange, CA, USA). Total RNA $(1 \mu \mathrm{g})$ was used to produce cDNA using the SuperScript II reverse transcriptase (Thermo Fisher Scientific). Primary denaturation of qRT-PCR was conducted as follows: 2 minutes at $94^{\circ} \mathrm{C}, 30$ seconds at $94^{\circ} \mathrm{C}, 30$ seconds at $58^{\circ} \mathrm{C}$, and 1 minute at $72^{\circ} \mathrm{C}$. After 35 amplification cycles, extra extension reactions were conducted for 10 minutes at $72^{\circ} \mathrm{C}$.

\section{MTT assay}

Plates with 96 wells were used to culture 2,000 cells in $100 \mu \mathrm{L}$ of media. Every well received an additional $10 \mu \mathrm{L}$ of MTT agent (Sigma-Aldrich Co., St Louis, MO, USA) at $5 \mathrm{mg} / \mathrm{mL}$ concentration. The media were drained after 4 hours. To promote the lysis of formazan crystals, $150 \mu \mathrm{L}$ of DMSO was added to every well. The absorbance was recorded at 490 nm using a Thermo Fisher Spectrophotometer 1510 (Molecular Devices LLC, Sunnyvale, CA, USA). The survival rate was calculated as a ratio of the absorbance of supplemented cells to that of the control groups. This process was repeated thrice.

\section{Apoptosis assay}

Subsequently, cells that received supplementation underwent 10 minute staining with Hoechst 33342 and were observed using UV/488 dual stimulation under an inverted fluorescence microscope (DM16000B, Leica Microsystems, Wetzlar, Germany). Fluorescence was evaluated against the emission of Hoechst 33342 dye at $460 \mathrm{~nm}$. Cell death manifested as fragmented nuclei. No $<200$ cells were assessed from five randomly selected fields.

\section{Western blot (WB)}

Cells were obtained and underwent washing with PBS. In order to obtain total protein to carry out WB, lysis buffer with protease suppressors was used. Proteins, totally $20 \mu \mathrm{g}$ from the lysates, were placed on a SDS-PAGE and underwent electrophoresis. Nitrocellulose membrane was utilized in order to transfer the protein blots. Blocking solution including PBS, 5\% skimmed milk, and 0.1\% Tween-20 was supplemented for 1 hour at room temperature. Subsequently, overnight incubation of primary antibodies (anti-EGFR, antiActin, as well as anti-p-EGFR; Abcam, Cambridge, MA, USA) was done at $4^{\circ} \mathrm{C}$. Tris-buffered saline containing $0.05 \%$ 
Tween-20, used for membrane bathing, was incubated for 90 minutes with secondary antibodies at room temperature. Enhanced chemiluminescence (ECL; Pierce, Rockford, IL, USA) was used to observe protein bands.

\section{Statistical analysis}

The outcome is presented in the form of mean \pm SD. Oneway ANOVA or Student's $t$-test was utilized to evaluate the difference. SPSS 17.0 (SPSS Inc., Chicago, IL, USA) was adopted to carry out analyses. Results of a two-tailed test were regarded as significant at $P<0.05$.

\section{Results}

\section{Extended ceritinib supplemented to LC cells brought about CR}

Repeated exposure to prolonged ceritinib addition was used to generate adaptive H1299 and HCC78 cells. Cells developed CR and were designated H1299R and HCC78R subsequent to intermittent ceritinib supplements $(1 \mu \mathrm{M})$ for 3 days. The two kinds of cells were cultured with ceritinib $(1 \mu \mathrm{M})$ to maintain resistance. CS in HCC78R and H1299R cells was lower by a factor of 10 times than that of the parent cells (Figure 1A and B). Furthermore, ceritinib supplementation triggered cell death in parent cells, a reaction thoroughly eliminated in not only HCC78R cells but also in H1299R cells (Figure 1C and D).

\section{Afatinib efficiently promoted CS in both ceritinib-resistant and ceritinib-sensitive NSCLC cells}

In order to explore whether afatinib was able to promote the suppressive effect of ceritinib on the proliferation of CS HCC78 and H1299 cells, the effect of afatinib on cell viability at different concentrations in both two ceritinibresistant cells and their parental cells was detected using the MTT assay first. The results showed that afatinib at
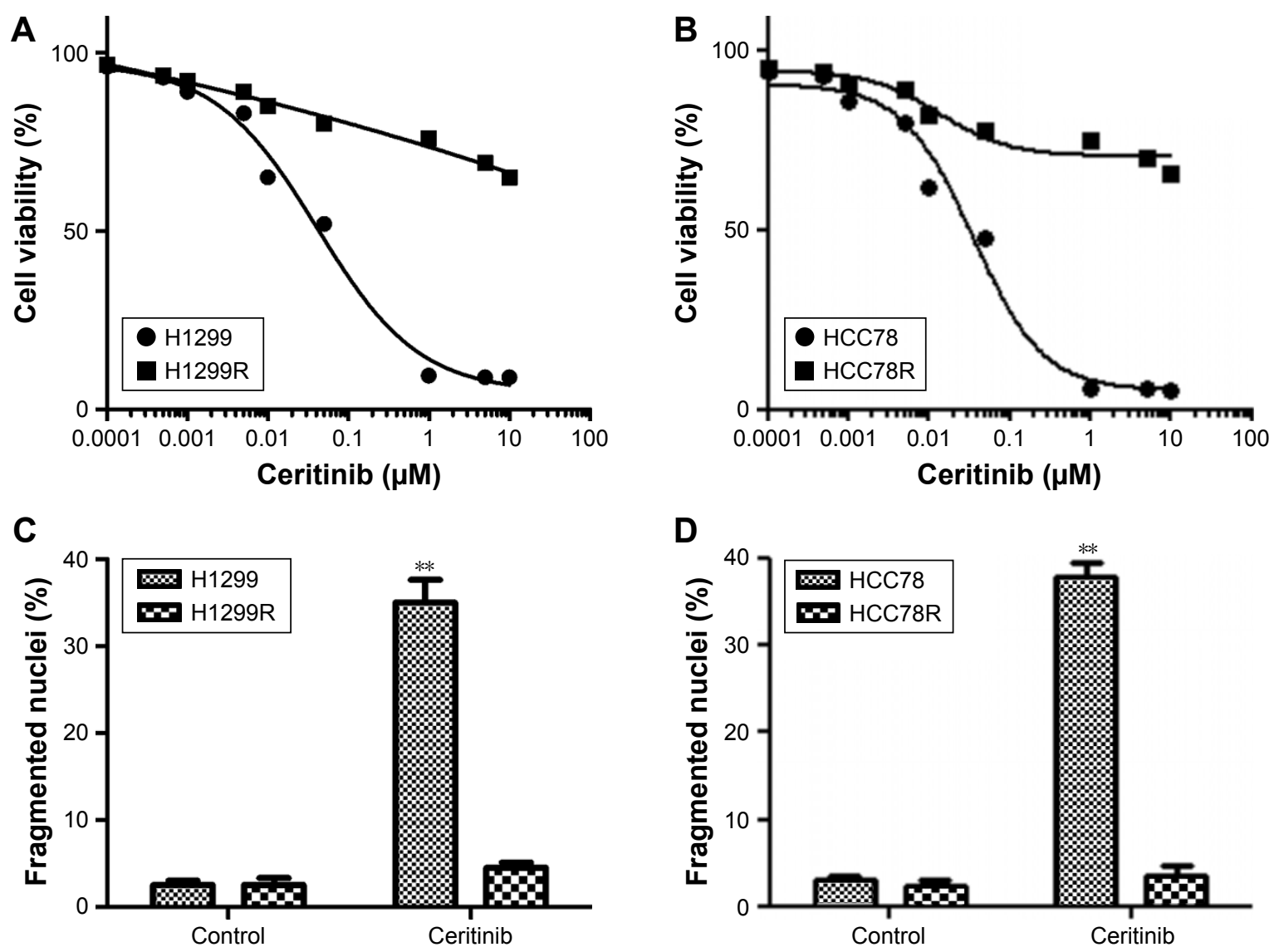

Figure I Extended therapy of human LC cells with ceritinib induced CR.

Notes: (A) HI299R (generated by ceritinib supplement to HI299 cells) and (B) HCC78R (generated by ceritinib supplement to HCC78 cells), as well as corresponding parent cells, received the supplement of ceritinib for 4 days. MTT assay was used to evaluate the survival. (C) HI299R and (D) HCC78R, as well as corresponding parent cells, received the supplement of $500 \mathrm{nM}$ ceritinib for 2 days. Calculation of fragmented as well as condensed nuclei was used to evaluate cell death. Data are presented as mean $\pm S D$ from three independent experiments. ${ }^{*} * P<0.0$ I, ceritinib vs control.

Abbreviations: CR, ceritinib resistance; LC, lung cancer. 
concentration $<0.5 \mu \mathrm{M}$ only gently impacted cell viability in both CR and parental cells. In contrast, high concentration of afatinib significantly suppressed the cell survival (Figure 2A and B). Supplement of ceritinib noticeably decelerated the growth of HCC87 and H1299 cells (Figure 2C and D).
These cells supplemented with afatinib (200 nM) experienced CS (Figure 2C and D). Furthermore, cell death triggered by ceritinib in both parent cells was remarkably promoted by treatment with both afatinib and ceritinib together (Figure 2E and F).
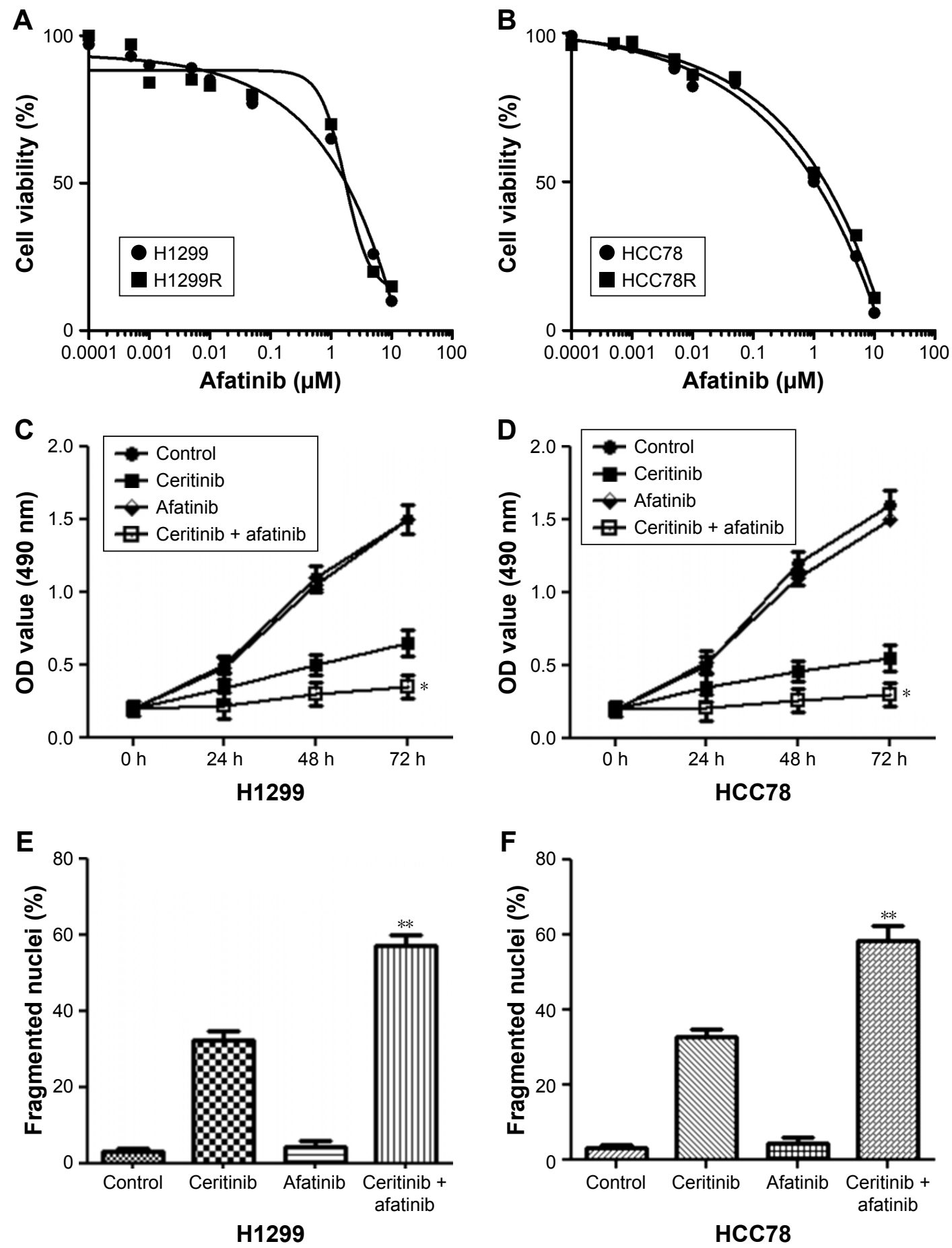

Figure 2 Afatinib promoted CS in CS LC cells.

Notes: (A) HI299R and (B) HCC78R, as well as corresponding parent cells, received supplement of afatinib for 4 days. MTT assay was used to evaluate the survival. (C) HI299 and (D) HCC78 cells received the supplement of $500 \mathrm{nM}$ ceritinib, $200 \mathrm{nM}$ afatinib, or both at specific time points. MTT assay was used to evaluate the survival. (E) HI299 and (F) HCC78 cells received the supplement of $500 \mathrm{nM}$ ceritinib, $200 \mathrm{nM}$ afatinib, or both for 2 days. Cell death was evaluated by the calculation of fragmented as well as condensed nuclei. Data are presented as mean \pm SD from three independent experiments. $* P<0.0$ I and $* * P<0.0$, ceritinib + afatinib vs ceritinib. Abbreviations: CS, ceritinib sensitivity; LC, lung cancer. 
Subsequently, our research investigated whether afatinib was able to attenuate CR in LC cells. Findings from MTT assays suggested that HCC78R and H1299R cells displayed stronger CR than did parent cells. However, afatinib addition noticeably promoted the CS of both resistant cell types (Figure 3A and B). Despite the fact that afatinib failed to promote cell death in these two resistant classes of cells, the combination of afatinib and ceritinib triggered cell death in $\sim 60 \%$ of HCC $78 \mathrm{R}$ and H1299R cells (Figure 3C and D).

\section{Afatinib decreased NRG I pathway stimulation in not only CS cells but also in $\mathrm{CR}$ cells}

In order to illuminate how afatinib counteracted acquired CR, our research investigated the effect of afatinib on stimulation of the NRG1-EGFR pathway, which was demonstrated to participate in CR. ${ }^{13}$ First, WB was done for both CS HCC78 and H1299 cells. The results showed that afatinib reduced the phosphorylation of EGFR with or without ceritinib, while ceritinib alone promoted its phosphorylation (Figure 4A and B). Reverse transcriptase-PCR (RT-PCR) revealed that transcription of EGF-like ligand NRG1 was elevated subsequent to ceritinib addition. Afatinib remarkably reduced NRG1 transcription with or without ceritinib (Figure 4C and D).

Taking into consideration the stimulation of NRG1 pathway in parent cells as well as CR cells, phosphorylation of EGFR and transcription of NRG1 were remarkably elevated in HCC78R and H1299R cells (Figure 5A-D). In conformity with ceritinib sensitivity (CS) cells, afatinib remarkably reduced the promoted phosphorylation of EGFR and transcription of NRG1 with or without ceritinib owing to the long-term supplementation of ceritinib (Figure 5A-D).
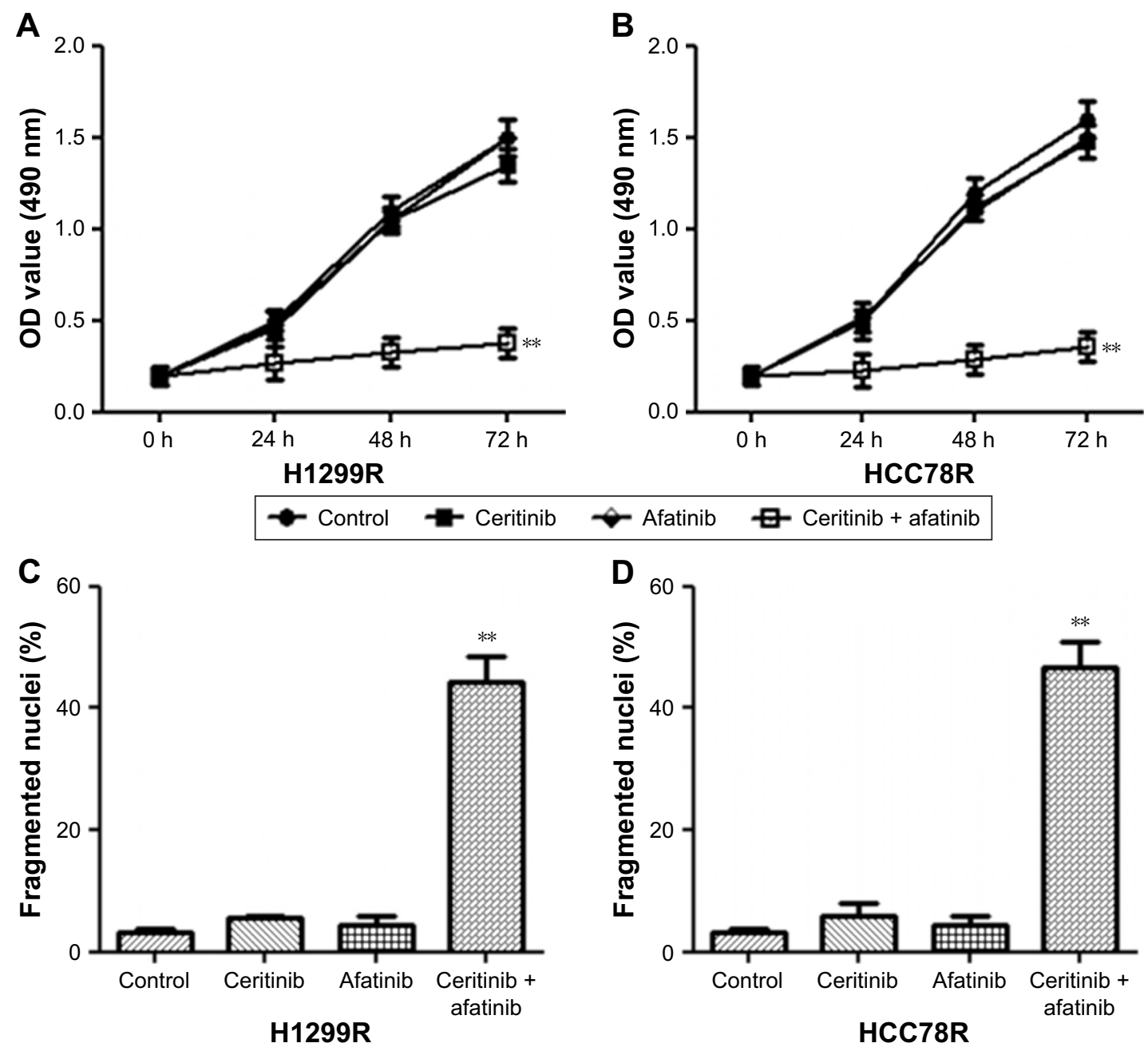

Figure 3 Afatinib promoted CS in CR LC cells.

Notes: (A) HI299R and (B) HCC78R cells received the supplement of $500 \mathrm{nM}$ ceritinib, $200 \mathrm{nM}$ afatinib, or both at specific time points. MTT assay was used to evaluate survival. (C) HI299R and (D) HCC78R cells received the supplement of $500 \mathrm{nM}$ ceritinib, $200 \mathrm{nM}$ afatinib, or both for 2 days. Cell death was evaluated by the calculation of fragmented as well as condensed nuclei. Data are presented as mean \pm SD from three independent experiments. $* * P<0.0$ I, ceritinib + afatinib vs ceritinib. Abbreviations: CS, ceritinib sensitivity; CR, ceritinib resistance; LC, lung cancer. 
A

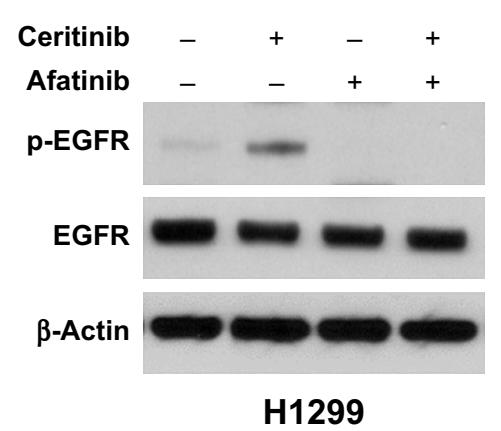

C

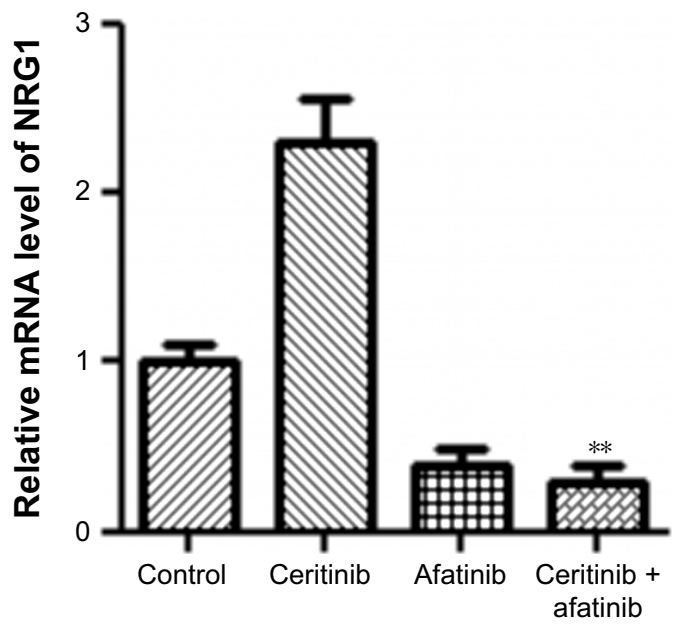

B

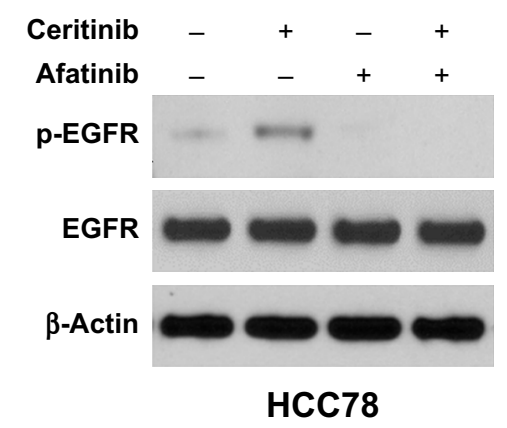

D

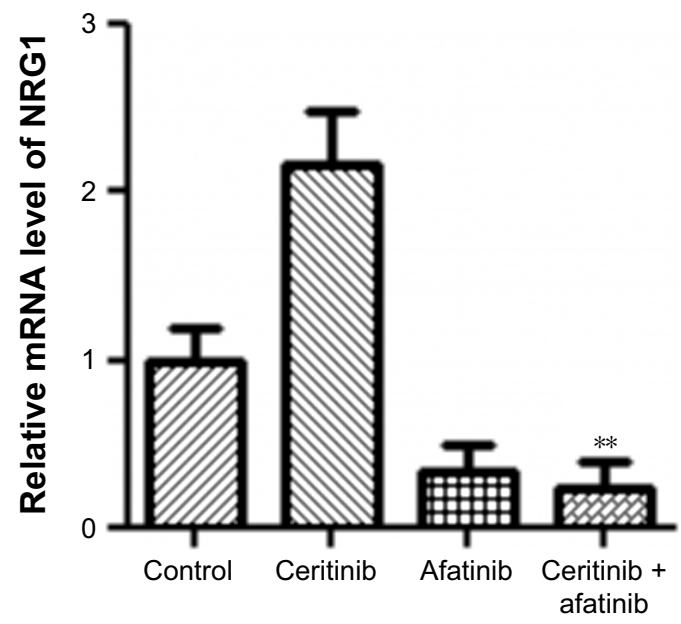

Figure 4 Afatinib decreased NRGI pathway stimulation in CS LC cells.

Notes: (A) HI299 and (B) HCC78 cells, as well as corresponding parent cells, received the supplement of $500 \mathrm{nM}$ ceritinib, $200 \mathrm{nM}$ afatinib, or both for 2 days. WB was used to evaluate the expression of certain proteins. (C-D) RT-PCR was used to assess NRGI transcription. Data are presented as mean \pm SD from three independent experiments. $* * P<0.01$, ceritinib + afatinib vs ceritinib.

Abbreviations: CS, ceritinib sensitivity; LC, lung cancer; WB, Western blot.

\section{Afatinib counteracted CR triggered by NRGI in human LC cells}

Forty-eight-hour culture in medium containing NRG1 reduced the CS of HCC78 and H1299 cells, as revealed by the MTT assay, but afatinib supplement recovered CS (Figure 6A and $\mathrm{B})$. Furthermore, the use of ceritinib and afatinib together remarkably triggered cell death in HCC78 and H1299 cells cultivated in media containing NRG1 (Figure 6C and D).

\section{Discussion}

This study demonstrated that afatinib can promote CS in CS cells and counteract CR in CR cells with the help of ceritinib. The counteracting influence of afatinib on CR was because of its capability to decrease NRG1 stimulation. Additionally, we established that the combination of both ceritinib and afatinib counteracted CR in NSCLC patients with positive ROS1 or ALK.

Rearrangement of ALK usually leads to remarkable reactions to the first generation of ALK suppressors including crizotinib. However, drug resistance occurs unavoidably. ${ }^{15-21}$ Apart from progress in the second generation of ALK suppressors, adding secondary agents with crizotinib could serve as an innovative strategy to counteract CR. Recent studies have explored the effect of the combined application of crizotinib and pemetrexed or some targeted reagents like an Hsp90 suppressor in terminal NSCLC with positive ALK. ${ }^{22}$ Since resistance to the second generation of ALK suppressors including ceritinib exists, ${ }^{23}$ investigation of the promising joint therapy could suggest innovative approaches to treat NSCLC with positive ALK or ROS1 instead of relying on the successful preparation of ALK suppressors.

As a member of the second generation of pan-EGFR tyrosine kinase inhibitor, which has received FDA approval, afatinib irreversibly binds to HER4, HER2, and EGFR1, ${ }^{24,25}$ leading to persistent suppression in comparison with the first generation of TKI suppressors, such as erlotinib and gefitinib. ${ }^{26,27}$ Previous research has demonstrated that 


\section{A}
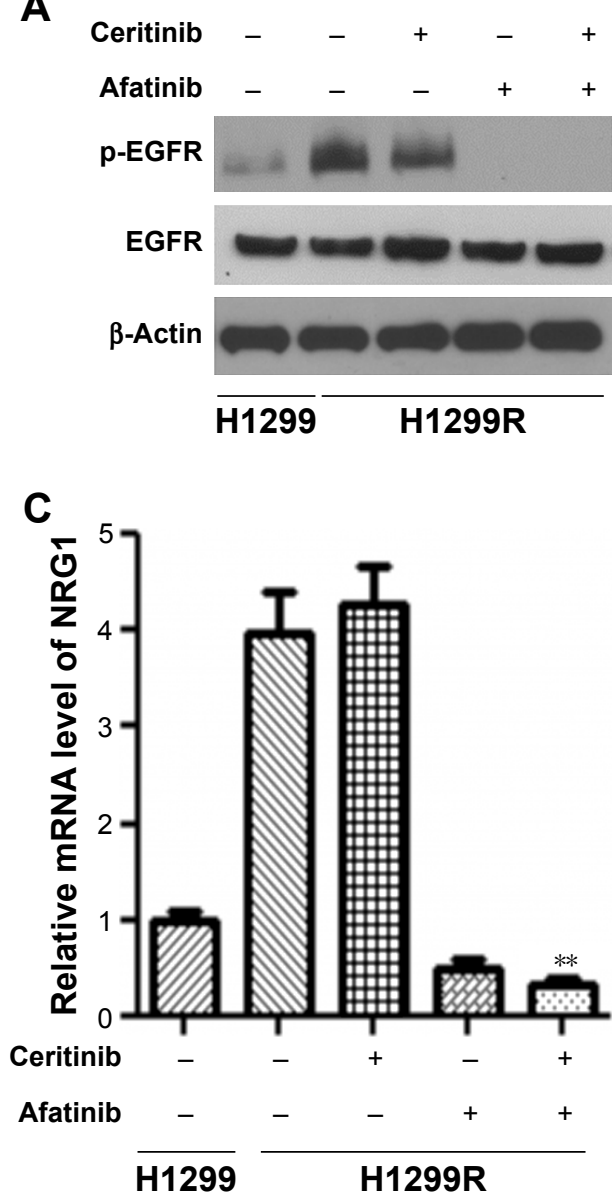

B
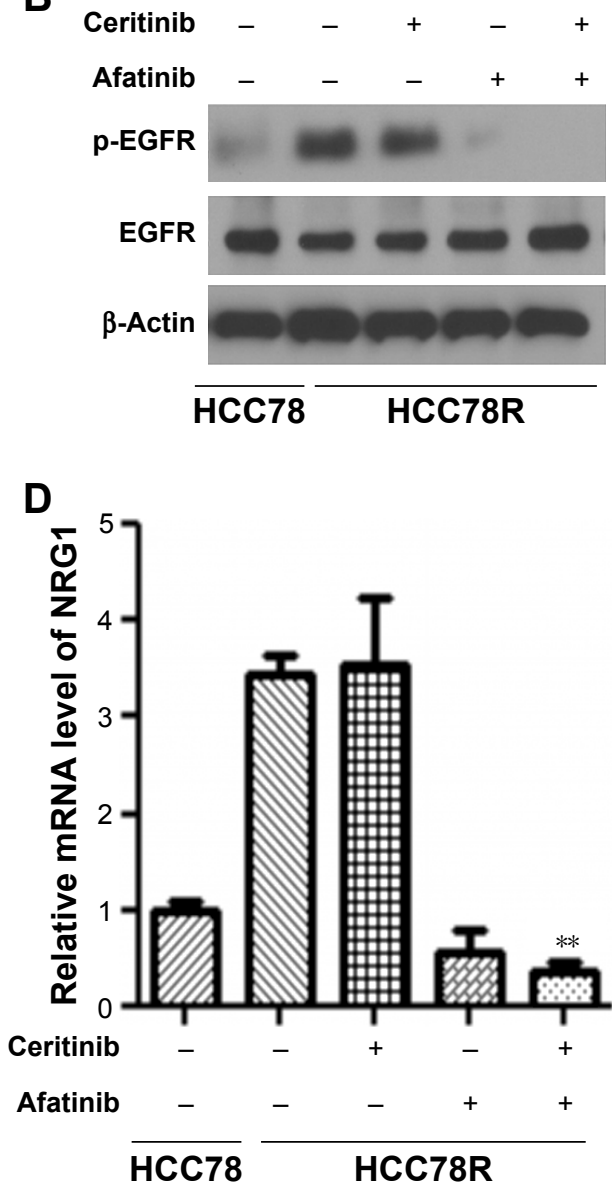

Figure 5 Afatinib decreased NRGI pathway stimulation in CR LC cells.

Notes: (A) HI299R and (B) HCC78R cells, as well as corresponding parent cells, received the supplement of $500 \mathrm{nM}$ ceritinib, $200 \mathrm{nM}$ afatinib, or both for 2 days. WB was used to evaluate the expression of certain proteins. (C-D) NRGI transcription was assessed by RT-PCR. Data are presented as mean \pm SD from three independent experiments. ${ }^{* *} P<0.0 \mathrm{I}$, ceritinib + afatinib vs ceritinib.

Abbreviations: CR, ceritinib resistance; LC, lung cancer; WB, Western blot.

afatinib remarkably suppresses the proliferation of tumors, which excessively express either wild-type HER2 and/or EGFR1 or EGFR1 with L858R/T790M dual mutations. ${ }^{26,27}$ Furthermore, it has been proved by in vitro studies in hypopharyngeal cell line FaDu that afatinib suppresses growth and promotes sensitivity to radiotherapy. ${ }^{24,25}$ In our study, afatinib supplementation promoted CS in HCC78 and H1299 cells. Furthermore, in terms of HCC78R and H1299R cells, the addition of afatinib counteracted resistance. Inhibited growth as well as promoted cell death could serve as the mechanism of the combination of two agents, which was evidenced via MTT and fragmented nuclei calculation.

Throwing light upon how afatinib counteracts CR is crucial to the generation of innovative reagents to treat ALK/ ROS1 NSCLC. Currently, NRG1-EGFR axis is related to CR. NRG1 concentration seems to be linked to the risk of human tumors. ${ }^{28}$ Generally, elevated levels of EGFR are linked to increased mortality. ${ }^{29,30}$ With studies available on specific suppressors of NRG1, indications that malignant cells with NRG1 expression could respond to EGFR suppressors and EGFR TKIs are able to decrease EGFR expression and downstream agents. ${ }^{31}$ One recent study also revealed that gene fusions involving the ERBB ligand gene, NRG1, might lead to the expression and presentation of the EGF-like domain of NRG1 on the cell surface, which binds to ERBB3 in an autocrine and juxtacrine manner, thus inducing the formation of ERBB2-ERBB3 heterodimers and subsequent activation of the PI3K-AKT and MAPK signaling pathways. ${ }^{32} \mathrm{We}$ discovered that afatinib supplement decreased the stimulation of NRG1 pathway in both parent cells and CR cells, which was expected. Furthermore, afatinib counteracted resistance triggered by NRG1 in both sets of parent cells. This indicates that afatinib counteracts $\mathrm{CR}$ via the suppression of NRG1 pathway. 
A

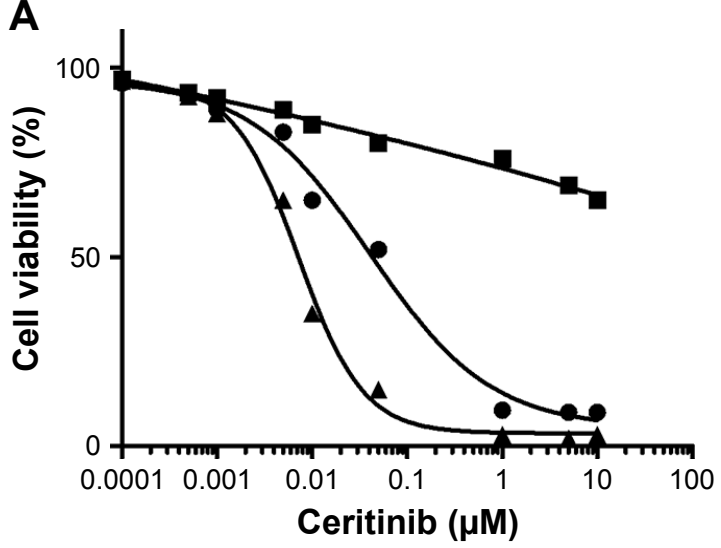

C
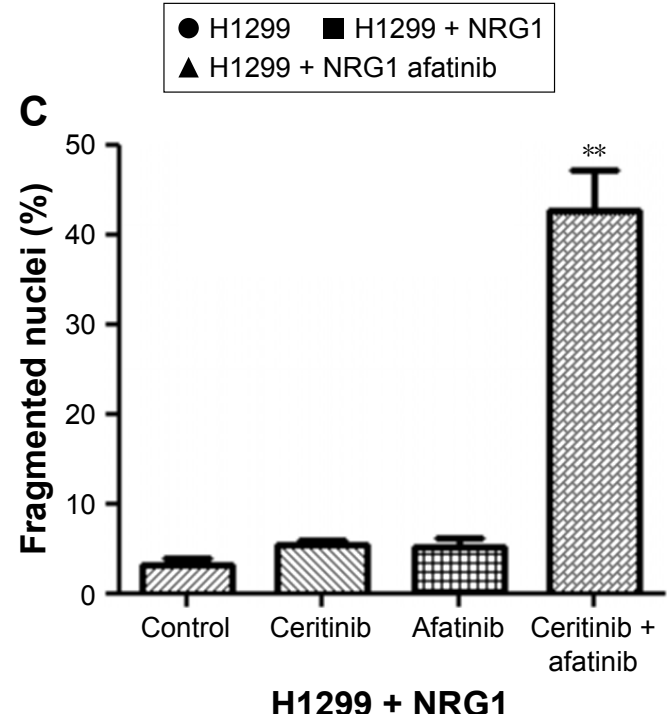

B

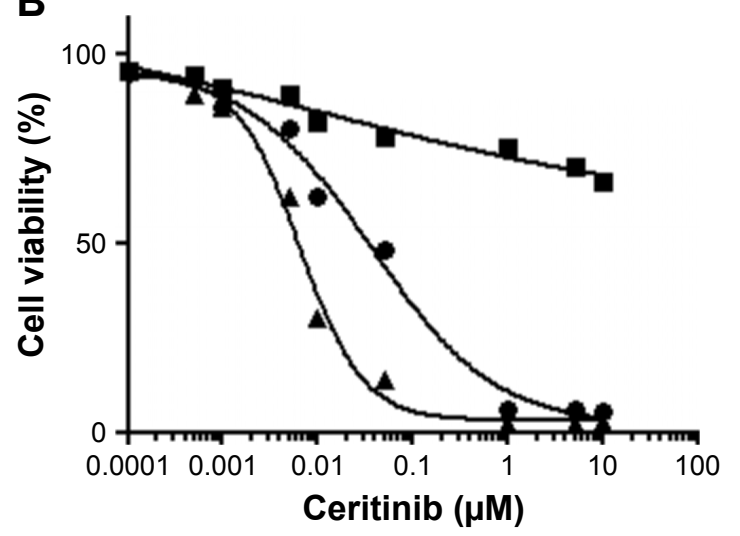

- HCC78 $\mathrm{HCC} 78+\mathrm{NRG} 1$

$\Delta$ HCC78 + NRG1 afatinib

D

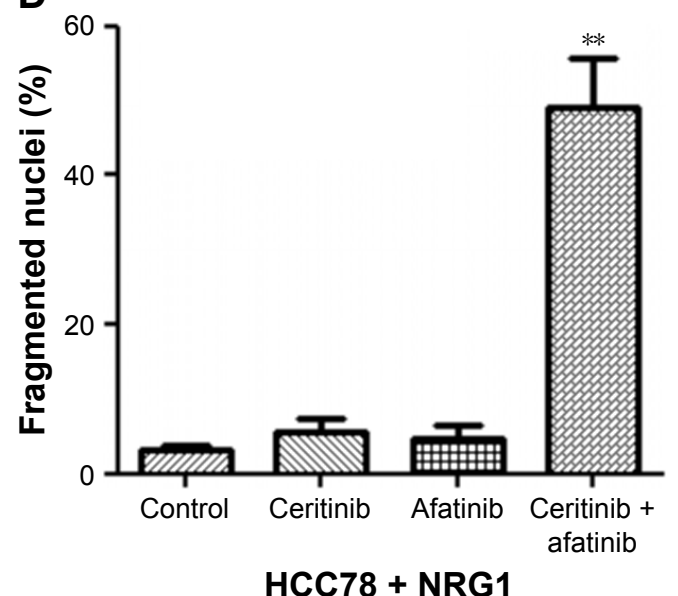

Figure 6 Afatinib counteracted CR triggered by NRGI in LC cells.

Notes: (A) HI299 and (B) HCC78 cells received the supplement of $100 \mathrm{ng} / \mathrm{mL}$ NRGI or $100 \mathrm{ng} / \mathrm{mL}$ NGRI and $200 \mathrm{nM}$ afatinib and subsequently underwent incubation with ceritinib for 4 days. MTT assay was used to evaluate the survival. (C) HI299 and (D) HCC78 cells received the supplement of I00 ng/mL of NRGI and subsequently underwent incubation with $500 \mathrm{nM}$ ceritinib, $200 \mathrm{nM}$ afatinib, or both for 2 days. Cell death was evaluated by the calculation of fragmented as well as condensed nuclei. Data are presented as mean \pm SD from three independent experiments. $* * P<0.01$, ceritinib + afatinib vs ceritinib.

Abbreviations: CR, ceritinib resistance; LC, lung cancer.

\section{Conclusion}

Our study elucidated that NRG1-HER3-EGFR participates in the regulation of CR in ALK/ROS1 NSCLC. Afatinib is able to counteract CR in ALK/ROS1 NSCLC cells by the inhibition of NRG1 axis, indicating a promising innovative approach to overcome CR in ALK/ROS1 NSCLC.

\section{Acknowledgments}

This work was supported by National Key Research and Development Program of China (grant number 2016YFC0905501 and 2016YFC0905500) and the National Natural Science Foundation of China (grant number 81772484).

\section{Author contributions}

$\mathrm{HC}$ conceived the study and designed the experiments. $\mathrm{HC}, \mathrm{QZ}, \mathrm{YZ}, \mathrm{BJ}$, and BZ contributed to data extraction, performed the analysis, and interpreted the results. CW wrote the first draft. HC, QY, YZ, BJ, and BZ contributed to the critical revision of the article. All authors contributed toward data analysis, drafting and critically revising the paper, gave approval of the final version to be published and agree to be accountable for all aspects of the work.

\section{Disclosure}

The authors report no conflicts of interest in this work.

\section{References}

1. Siegel RL, Miller KD, Jemal A. Cancer statistics, 2016. CA Cancer J Clin. 2016;66(1):7-30.

2. Kwak EL, Bang YJ, Camidge DR, et al. Anaplastic lymphoma kinase inhibition in non-small-cell lung cancer. $N$ Engl J Med. 2010;363(18): 1693-1703.

3. Soda M, Choi YL, Enomoto M, et al. Identification of the transforming EML4-ALK fusion gene in non-small-cell lung cancer. Nature. 2007; 448(7153):561-566. 
4. Bergethon K, Shaw AT, Ou SH, Shi O, et al. ROS1 rearrangements define a unique molecular class of lung cancers. J Clin Oncol. 2012; 30(8):863-870.

5. Takeuchi K, Soda M, Togashi Y, et al. RET, ROS1 and ALK fusions in lung cancer. Nat Med. 2012;18(3):378-381.

6. Friboulet L, Li N, Katayama R, et al. The ALK inhibitor ceritinib overcomes crizotinib resistance in non-small cell lung cancer. Cancer Discov. 2014;4(6):662-673.

7. Shen L, Ji HF. Ceritinib in ALK-rearranged non-small-cell lung cancer. $N$ Engl J Med. 2014;370(26):2537.

8. Vansteenkiste JF. Ceritinib for treatment of ALK-rearranged advanced non-small-cell lung cancer. Future Oncol. 2014;10(12):1925-1939.

9. Toyokawa G, Inamasu E, Shimamatsu S, et al. Identification of a Novel ALK G1123S Mutation in a Patient with ALK-rearranged Non-smallcell Lung Cancer Exhibiting Resistance to Ceritinib. Journal of Thoracic Oncology. 2015;10(7):e55-e57.

10. Kodityal S, Elvin JA, Squillace R, et al. A novel acquired ALK F1245C mutation confers resistance to crizotinib in ALK-positive NSCLC but is sensitive to ceritinib. Lung Cancer. 2016;92:19-21.

11. Buac K, Xu M, Cronin J, Weeraratna AT, Hewitt SM, Pavan WJ NRG1/ERBB3 signaling in melanocyte development and melanoma: inhibition of differentiation and promotion of proliferation. Pigment Cell Melanoma Res. 2009;22(6):773-784.

12. Dong X, Fernandez-Salas E, Li E, Wang S. Elucidation of Resistance Mechanisms to Second-Generation ALK Inhibitors Alectinib and Ceritinib in Non-Small Cell Lung Cancer Cells. Neoplasia. 2016;18(3): $162-171$

13. Sequist LV, Yang JC, Yamamoto N, et al. Phase III study of afatinib or cisplatin plus pemetrexed in patients with metastatic lung adenocarcinoma with EGFR mutations. J Clin Oncol. 2013;31(27):3327-3334.

14. $\mathrm{Wu} \mathrm{YL,} \mathrm{Zhou} \mathrm{C,} \mathrm{Hu} \mathrm{CP,} \mathrm{et} \mathrm{al.} \mathrm{Afatinib} \mathrm{versus} \mathrm{cisplatin} \mathrm{plus} \mathrm{gemcitabine}$ for first-line treatment of Asian patients with advanced non-small-cell lung cancer harbouring EGFR mutations (LUX-Lung 6): an open-label, randomised phase 3 trial. Lancet Oncol. 2014;15(2):213-222.

15. Doebele RC, Pilling AB, Aisner DL, et al. Mechanisms of resistance to crizotinib in patients with ALK gene rearranged non-small cell lung cancer. Clin Cancer Res. 2012;18(5):1472-1482.

16. Chen Z, Akbay E, Mikse O, et al. Co-clinical trials demonstrate superiority of crizotinib to chemotherapy in ALK-rearranged non-small cell lung cancer and predict strategies to overcome resistance. Clin Cancer Res. 2014;20(5):1204-1211.

17. Song A, Kim TM, Kim DW, et al. Molecular Changes Associated with Acquired Resistance to Crizotinib in ROS1-Rearranged Non-Small Cell Lung Cancer. Clin Cancer Res. 2015;21(10):2379-2387.

18. Casaluce F, Sgambato A, Sacco PC, et al. Resistance to Crizotinib in Advanced Non-Small Cell Lung Cancer (NSCLC) with ALK Rearrangement: Mechanisms, Treatment Strategies and New Targeted Therapies. Curr Clin Pharmacol. 2016;11(2):77-87.
19. Cuyàs E, Pérez-Sánchez A, Micol V, Menendez JA, Bosch-Barrera J STAT3-targeted treatment with silibinin overcomes the acquired resistance to crizotinib in ALK-rearranged lung cancer. Cell Cycle. 2016; 15(24):3413-3418.

20. Zhong E, Huang H. Crizotinib in ROS1 rearranged non-small cell lung cancer (NSCLC), from response to resistance. BMJ Case Rep. 2016;2016:bcr2016217322.

21. Zhang L, Jiang T, Li X, et al. Clinical features of Bim deletion polymorphism and its relation with crizotinib primary resistance in Chinese patients with ALK/ROS1 fusion-positive non-small cell lung cancer. Cancer. 2017;123(15):2927-2935.

22. Iacono D, Chiari R, Metro G, et al. Future options for ALK-positive non-small cell lung cancer. Lung Cancer. 2015;87(3):211-219.

23. Toyokawa G, Inamasu E, Shimamatsu S, et al. Identification of a Novel ALK G1123S Mutation in a Patient with ALK-rearranged Non-smallcell Lung Cancer Exhibiting Resistance to Ceritinib. J Thorac Oncol. 2015;10(7):e55-e57.

24. Li D, Ambrogio L, Shimamura T, et al. BIBW2992, an irreversible EGFR/HER2 inhibitor highly effective in preclinical lung cancer models. Oncogene. 2008;27(34):4702-4711.

25. Solca F, Dahl G, Zoephel A, et al. Target binding properties and cellular activity of afatinib (BIBW 2992), an irreversible ErbB family blocker J Pharmacol Exp Ther. 2012;343(2):342-350.

26. Ferrarotto R, Gold KA. Afatinib in the treatment of head and neck squamous cell carcinoma. Expert Opin Investig Drugs. 2014;23(1): 135-143.

27. Modjtahedi H, Cho BC, Michel MC, Solca F. A comprehensive review of the preclinical efficacy profile of the ErbB family blocker afatinib in cancer. Naunyn Schmiedebergs Arch Pharmacol. 2014;387(6): 505-521.

28. Sheng Q, Liu X, Fleming E, et al. An activated ErbB3/NRG1 autocrine loop supports in vivo proliferation in ovarian cancer cells. Cancer Cell. 2010;17(3):298-310.

29. Chen HJ, Yan HH, Yang JJ, et al. Disease flare after EGFR tyrosine kinase inhibitor cessation predicts poor survival in patients with nonsmall cell lung cancer. Pathol Oncol Res. 2013;19(4):833-838.

30. Traynor AM, Weigel TL, Oettel KR, et al. Nuclear EGFR protein expression predicts poor survival in early stage non-small cell lung cancer. Lung Cancer. 2013;81(1):138-141.

31. Nakaoku T, Tsuta K, Ichikawa H, et al. Druggable oncogene fusions in invasive mucinous lung adenocarcinoma. Clin Cancer Res. 2014; 20(12):3087-3093.

32. Fernandez-Cuesta L, Thomas RK. Molecular Pathways: Targeting NRG1 Fusions in Lung Cancer. Clin Cancer Res. 2015;21(9):1989-1994.

OncoTargets and Therapy

\section{Publish your work in this journal}

OncoTargets and Therapy is an international, peer-reviewed, open access journal focusing on the pathological basis of all cancers, potential targets for therapy and treatment protocols employed to improve the management of cancer patients. The journal also focuses on the impact of management programs and new therapeutic agents and protocols on

\section{Dovepress}

patient perspectives such as quality of life, adherence and satisfaction. The manuscript management system is completely online and includes a very quick and fair peer-review system, which is all easy to use. Visit http://www.dovepress.com/testimonials.php to read real quotes from published authors. 